\title{
A Review of the Potential of Phytochemicals from Prunus africana (Hook f.) Kalkman Stem Bark for Chemoprevention and Chemotherapy of Prostate Cancer
}

\author{
Richard Komakech, ${ }^{1,2,3}$ Youngmin Kang, ${ }^{1,2}$ Jun-Hwan Lee, ${ }^{1,2}$ and Francis Omujal,4 \\ ${ }^{1}$ University of Science \& Technology (UST), Korean Medicine Life Science, Daejeon 34054, Republic of Korea \\ ${ }^{2}$ Korea Institute of Oriental Medicine (KIOM), Yuseongdae-ro, Yuseong-gu, Daejeon 34054, Republic of Korea \\ ${ }^{3}$ Natural Chemotherapeutics Research Institute (NCRI), Ministry of Health, P.O. Box 4864, Kampala, Uganda \\ ${ }^{4}$ Makerere University, P.O. Box 7062, Kampala, Uganda
}

Correspondence should be addressed to Youngmin Kang; ymkang@kiom.re.kr

Received 6 December 2016; Accepted 22 January 2017; Published 13 February 2017

Academic Editor: Dan Gincel

Copyright (C) 2017 Richard Komakech et al. This is an open access article distributed under the Creative Commons Attribution License, which permits unrestricted use, distribution, and reproduction in any medium, provided the original work is properly cited.

\begin{abstract}
Prostate cancer remains one of the major causes of death worldwide. In view of the limited treatment options for patients with prostate cancer, preventive and treatment approaches based on natural compounds can play an integral role in tackling this disease. Recent evidence supports the beneficial effects of plant-derived phytochemicals as chemopreventive and chemotherapeutic agents for various cancers, including prostate cancer. Prunus africana has been used for generations in African traditional medicine to treat prostate cancer. This review examined the potential roles of the phytochemicals from $P$. africana, an endangered, subSaharan Africa plant in the chemoprevention and chemotherapy of prostate cancer. In vitro and in vivo studies have provided strong pharmacological evidence for antiprostate cancer activities of $P$. africana-derived phytochemicals. Through synergistic interactions between different effective phytochemicals, P. africana extracts have been shown to exhibit very strong antiandrogenic and antiangiogenic activities and have the ability to kill tumor cells via apoptotic pathways, prevent the proliferation of prostate cancer cells, and alter the signaling pathways required for the maintenance of prostate cancer cells. However, further preclinical and clinical studies ought to be done to advance and eventually use these promising phytochemicals for the prevention and chemotherapy of human prostate cancer.
\end{abstract}

\section{Introduction}

Prostate cancer is one of the most common nonskin cancers in men. It is caused by unregulated prostate cell division, which leads to abnormal growth, with the potential to spread to other parts of the body [1]. These neoplastic cells originate from highly specialized cells through a process of regression to an advanced stage. Unlike the normal parent cells, these cells divide continuously, resulting in a tumor. Approximately, 9-11\% of men are at risk of clinically suffering from prostate cancer in their life time [2-5]. Prostate cancer is typically androgen-dependent during its initial stages when the hormone androgen binds to the androgen receptor $(A R)$ and then transactivates target genes $[6,7]$.
Androgen and AR-mediated signaling are therefore crucial for the development and functioning of both the normal prostate and prostate cancer. The importance of androgen in prostate cancer is further supported by the fact that prostate cancer rarely occurs in men with the deficiency in $5 \alpha$ reductase, an enzyme that converts testosterone to its active metabolite $5 \alpha$-dihydrotestosterone (DHT) [8]. Currently, one of the main approaches to the treatment of prostate cancer is downregulation of androgens by antiandrogenic agents $[5,6,9,10]$. For years, prostate cancer, similar to other forms of cancer, has been managed through the conventional treatment modalities such as surgery, radiation therapy, cryosurgery, and hormone therapies [11]. However, there is still no effective treatment for advanced stages of prostate 
cancer. Prostate cancer has been known to progress slowly and it is crucial to prevent its occurrence to reduce the risk of development of the disease. Chemoprevention and chemotherapy, including the administration of one or more naturally occurring antiprostate cancer agents $[1,3,4,10]$ have been identified as approaches by which the prevalence of such diseases as prostate cancer can be reduced, suppressed, or reversed. In the last decades, several plants have been confirmed to contain chemopreventive and therapeutic agents for various cancers including prostate cancer $[10,12-$ 14]. More importantly, over $60 \%$ of currently used anticancer agents are estimated to be from natural sources [13]. Among plants with enormous antiprostate cancer potential is Prunus africana (African cherry), which belongs to the plant family Rosaceae. This evergreen miraculous plant is only found in sub-Saharan Africa and is highly sought after owing to its unique anticancer phytochemicals $[1,2,15]$. In fact, the use of $P$. africana in African traditional medicine (ATM) to treat prostate cancer and related conditions is not a new phenomenon across various communities in Africa [1]. More importantly, the use of $P$. africana has been patented in France for prostate cancer treatment [16]. In addition to prostate cancer, the bark extract of $P$. africana has for many years been used for the treatment of benign prostatic hyperplasia $(\mathrm{BPH})$. Recent studies by Nyamai et al. [17] and Jena et al. [18] confirmed the effectiveness of the bark extract of $P$. africana in $\mathrm{BPH}$ treatment and attributed this to the synergistic effects of pentacyclic triterpenoids, ferulic esters of long-chain fatty alcohols, and phytosterols contained in $P$. africana bark. The phytosterols (including $\beta$-Sitosterol) and pentacyclic triterpenoids (including ursolic acids) also have anti-inflammatory effects on the prostate [17]. In ATM, P. africana is also used to treat myriad of diseases including but not limited to diarrhea, epilepsy, arthritis, hemorrhage, and hypertension $[15,16,19-21]$. The novel phytochemicals from $P$. africana, suggested for the treatment of prostate cancer are ursolic acid, oleanolic acid, $\beta$-amyrin, atraric acid (AA), N-butylbenzene-sulfonamide (NBBS), $\beta$-sitosterol, $\beta$ sitosterol-3-O-glucoside, ferulic acid, and lauric acid [20, 21]. The use of $P$. africana in cancer chemotherapy and chemoprevention has been discussed in a number of peer reviewed journal articles. This review therefore sought to examine the phytochemicals from $P$. africana that have the potential for prostate cancer chemoprevention and chemotherapy-both in vitro and in vivo with the goal of finding new drugs for prostate cancer.

\section{Methods}

In this review, we modified the data search process used by Kim et al. [47] and Lin et al. [48] to obtain information from original peer reviewed articles published in scientific journals, with a focus on the botany, distribution, and potential of $P$. africana for cancer chemoprevention and chemotherapy. We carefully searched electronic literature databases including but not limited to PubMed, Scopus, and Google Scholar for relevant records for a period from 1995 to 2016. The following key search terms were used ("P. africana"
OR "African cherry" OR "Pygeum africanum" AND "Prostate cancer" OR "Distribution" OR "Phytochemicals") OR ("Phytochemicals in P. africana" AND "Prostate cancer"), OR ("Chemotherapy" OR "Chemoprevention" OR "Treatment" AND "Prostate cancer") OR ("African traditional medicine" AND "Prostate cancer") OR ("Prunus africana phytochemicals” AND "Apoptosis" OR “Androgen receptors" OR "Cell proliferation" OR "Anti-prostate cancer properties"). The data obtained were verified independently for their accuracy and any inconsistencies were settled through discussions between the authors. The final data obtained through discussions among the authors were then summarized, analyzed, and compared, and conclusions were made accordingly.

\section{Prunus africana Botany and Distribution}

The genus Prunus comprises over 400 species, of which only 98 are of great importance [50]. The African cherry is a species of the genus Prunus, with a mature stem diameter of up to $1 \mathrm{~m}$ and a height of more than $40 \mathrm{~m}$ with open branches (Figure 1(a)); and a blackish-brown bark (Figure 1(b)). Leaves are simple, alternate, oval-shaped, shiny-deep green on the top side and lighter on the underside, with a conspicuous prominent midrib on the underside (Figure 1(c)). Flowers are greenish or white (Figure $1(\mathrm{~d})$ ), and fruits are spherical, $7 \mathrm{~mm}$ long, $1.3 \mathrm{~cm}$ wide, pinkish-brown, and bilobed, with thin, dark red to reddish brown pulp when ripe (Figure 1(e)) [20].

The genus name "Prunus" is derived from a Latin word which refers to the plum family, and the scientific name "Prunus africana" refers to the species of African origin. This monoecious tree is native to 21 countries in sub-Saharan Africa (Figure 2) $[19,51,52]$. It is a highland forest plant that grows in humid and semihumid conditions at an altitude of about $900-3,400 \mathrm{~m}$ above the sea level, with a mean annual rainfall of $890-2,600 \mathrm{~mm}$ and a mean annual temperature of $18-26^{\circ} \mathrm{C}[20,53]$.

The discovery of the medicinal properties of the $P$. africana bark for a myriad of health conditions initiated a massive harvest of its stem bark for international market needs [54]. To date, there has been an increasing demand for the bark of $P$. africana both locally and internationally, for the production of herbal medicines for the treatment of prostate cancer and related conditions [20]. Unfortunately, in most scenarios, it is the stem bark of the plant that is targeted (Figure 1(b)), which puts the survival of the plant at a great risk, if not done in accordance with the guidelines. In fact, poor harvest practices coupled with overexploitation has severely affected the wild population of $P$. africana $[55,56]$. Consequently, $P$. africana has been added to Appendix II of the Convention on International Trade in Endangered Species of Wild Fauna and Flora (CITES) list of endangered species, for the regulation of its trade from wild harvest and all exports of $P$. africana are currently subjected to a CITES export permit to protect the plant from extinction [51]. 


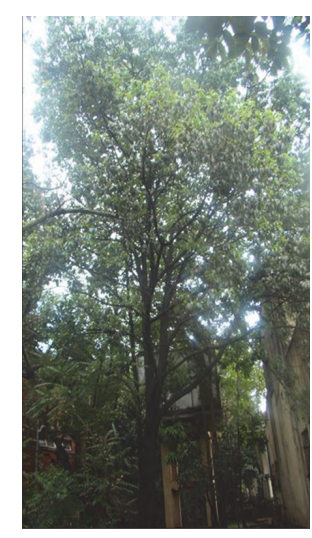

(a)

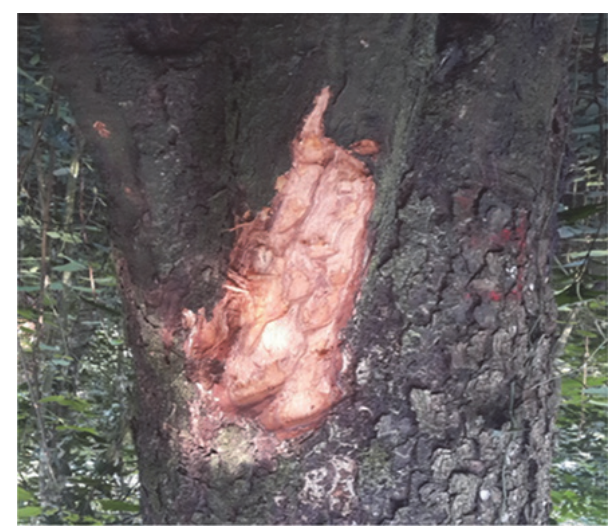

(b)

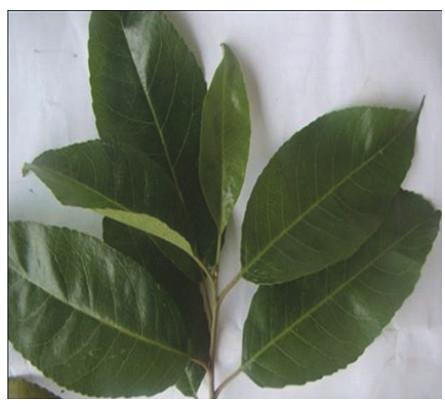

(c)

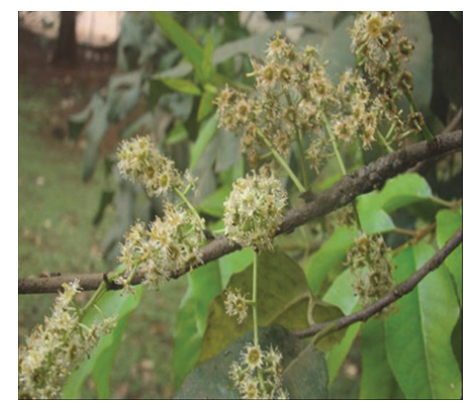

(d)

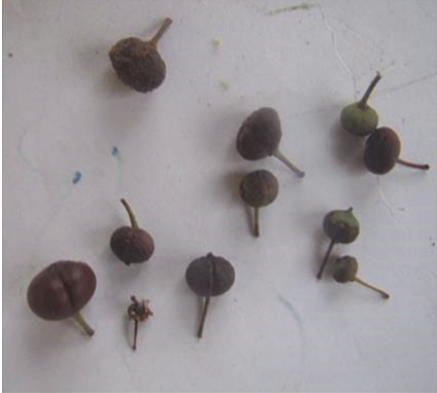

(e)

FIGURE 1: The botanical morphology of the main features of $P$. africana. (a) P. africana tree growing at backyard of Natural Chemotherapeutics Research Institute, Uganda. (b) Blackish-brown bark of $P$. Africana. (c) Simple, alternate, oval-shaped, leaf of $P$. Africa. (d) Greenish or white flowers of $P$. Africana. (e) Spherical, pinkish-brown, bilobed, fruit of P. africana.

\section{In Vitro and In Vivo Effects of Ethanolic Stem Bark Extracts of $P$. africana on Prostate Cancer Cells}

P. africana is one of the many medicinal plants containing large quantities of bioactive compounds that can be used for prostate cancer management $[15,20,22,57]$. Previous studies have shown that $P$. africana extracts as an antiprostate cancer treatment targets fast dividing cells by impairing mitosis or by causing target cells to undergo apoptosis [1, 20, 57]. Apoptosis is a biological process that occurs through a series of programmed cell death steps characterized by morphological alterations, including plasma and nuclear membrane blebbing, cell shrinkage, dissolution of the nuclear lamina, and biochemical processes responsible for the activation of apoptosis [58]. In a tissue culture study performed by Shenouda et al. [40], ethanolic extracts of $P$. africana showed growth inhibition of a human prostate cancer cell line (PC3 ) and epithelial cells derived from a lymph-node carcinoma of the prostate (LNCaP) by $50 \%$ at $2.5 \mu \mathrm{L} / \mathrm{mL}$ and also induced significant apoptosis in both cell lines (PC-3 and $\mathrm{LNCaP}$ ) at $2.5 \mu \mathrm{L} / \mathrm{mL}$ compared to untreated cells. In an in vivo study using TRAMP (transgenic adenocarcinoma of the mice prostate), a model for the pathogenesis of human prostate cancer, the mice that were fed on $P$. africana extract showed a significant reduction $(p=0.034)$ in the prostate cancer incidence (35\%) compared to casein fed mice $(62.5 \%)$ [40]. In another study by Margalef et al. [59], they observed that $P$. africana ethanolic extract had an antimitogenic effect on prostate cancer cells by inhibiting the mitogenic action of epidermal growth factor which resulted in a decreased number of cells entering the S-phase of the cell cycle. Thus, preclinical findings have shown that $P$. africana has a large potential in the regulation of prostate cancer by inhibiting the growth of prostate cancer cell lines and causing apoptosis both in vitro and in vivo. Hence, $P$. africana phytochemicals can be used as an effective cytotoxic chemotherapy in the treatment of men with prostate cancer and other prostate related conditions.

\section{Pharmacological Efficacy of Antiprostate Cancer Phytochemicals from P. africana}

The antiprostate cancer phytochemicals from $P$. africana can be divided into three major categories based on their targets and pharmacological effects (Table 1): (i) phytochemicals that kill the tumor cells through apoptotic pathways, a common mode of action of chemotherapeutic agents against a wide variety of cancer cells [60], (ii) phytochemicals that alter the signaling pathways required for the maintenance of prostate cancer cells, and (iii) phytochemicals that exhibit strong antiandrogenic and antiangiogenic activities. The details of 


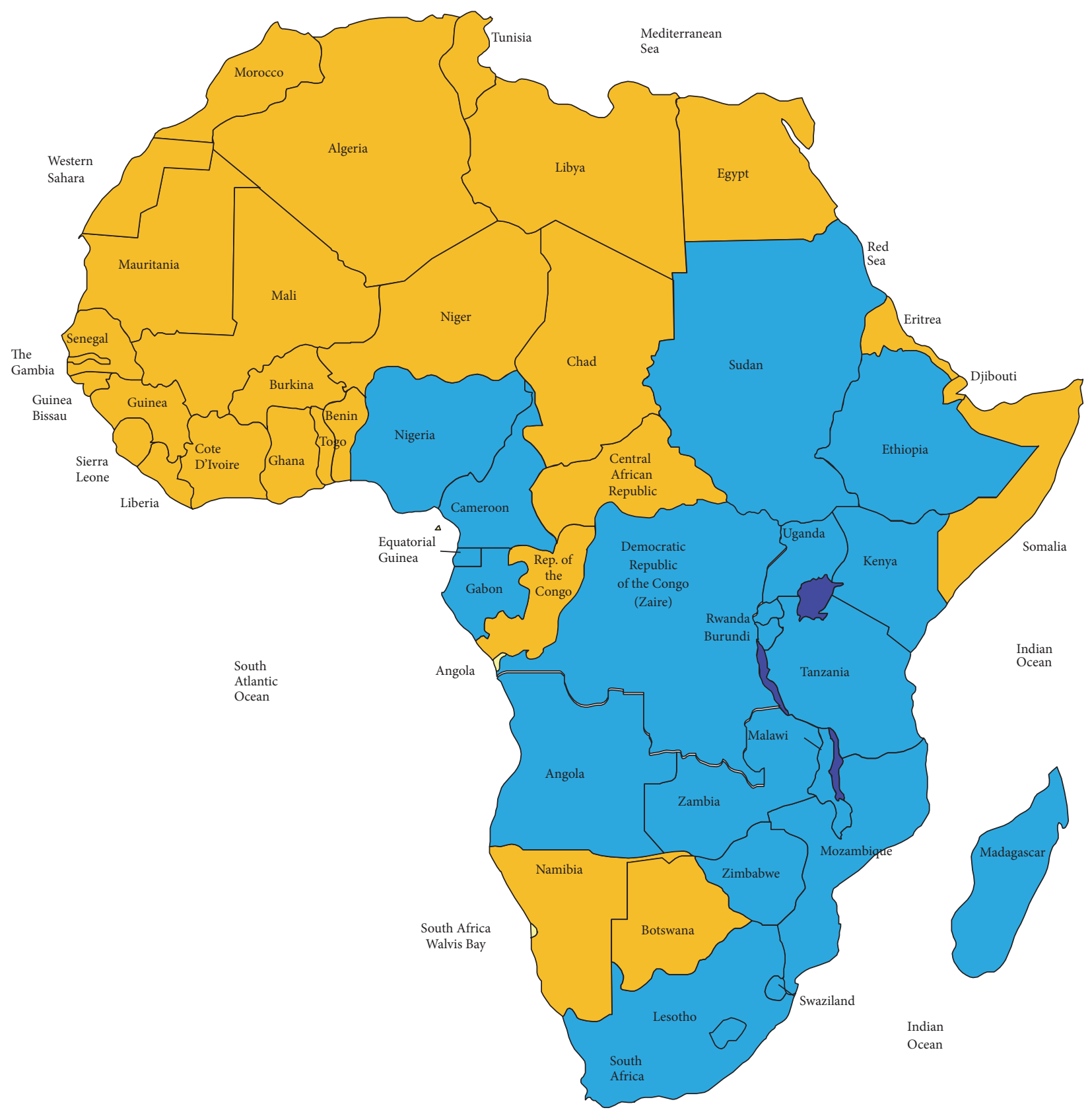

Indicates countries in which Prunus africana is distributed

Figure 2: Modified map from Hall et al. [49] on distribution of P. africana.

the antiprostate cancer effects of each phytochemical are shown in Table 1.

5.1. Ursolic Acid. Ursolic acid (Table 1(a)) is a pentacyclic triterpene compound isolated from many types of medicinal plants and widely present in human diet $[23,28]$. Several studies have suggested that ursolic acid is one of the main antiprostate cancer phytochemicals found in both root and stem bark extracts of $P$. africana $[2,22,24,25]$. This acid has been suggested to suppress inflammation, reduce oxidative stress, regulate cell cycle, inhibit cell proliferation, induce apoptosis, and interact with the tumor microenvironment through modulation of multiple signal transduction pathways $[22,26]$. A study has shown that the inhibition of cell viability and the induction of apoptosis in PC-3 and LNCaP cells by ursolic acid were associated with downregulation of the B-Cell Lymphoma 2 (BCL-2) protein [23], a member of the protein cell family that controls apoptosis to prevent prostate cancer progression $[27,28]$. This crucially proves the ability of ursolic acid to treat human prostate cancer, 


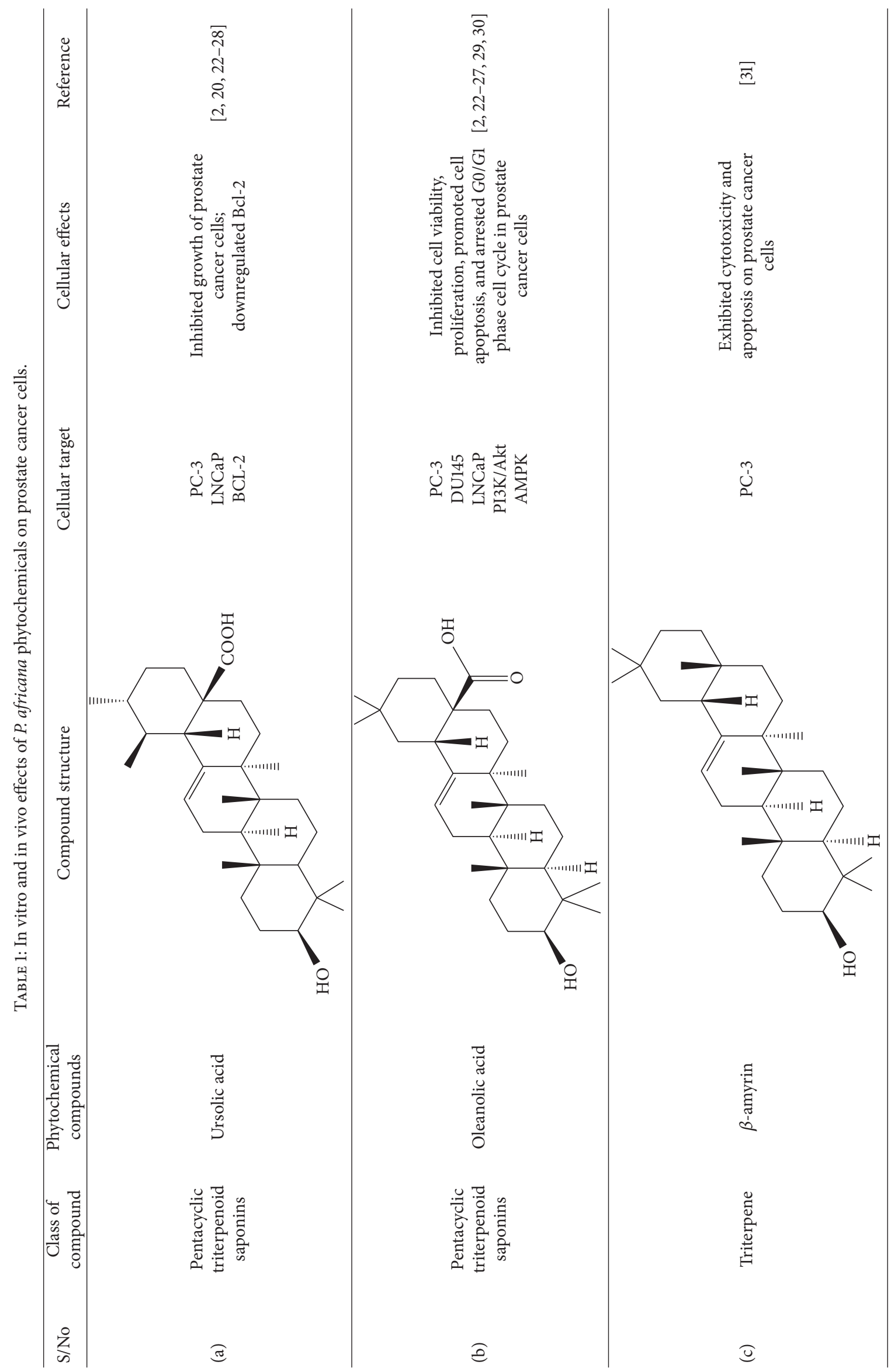




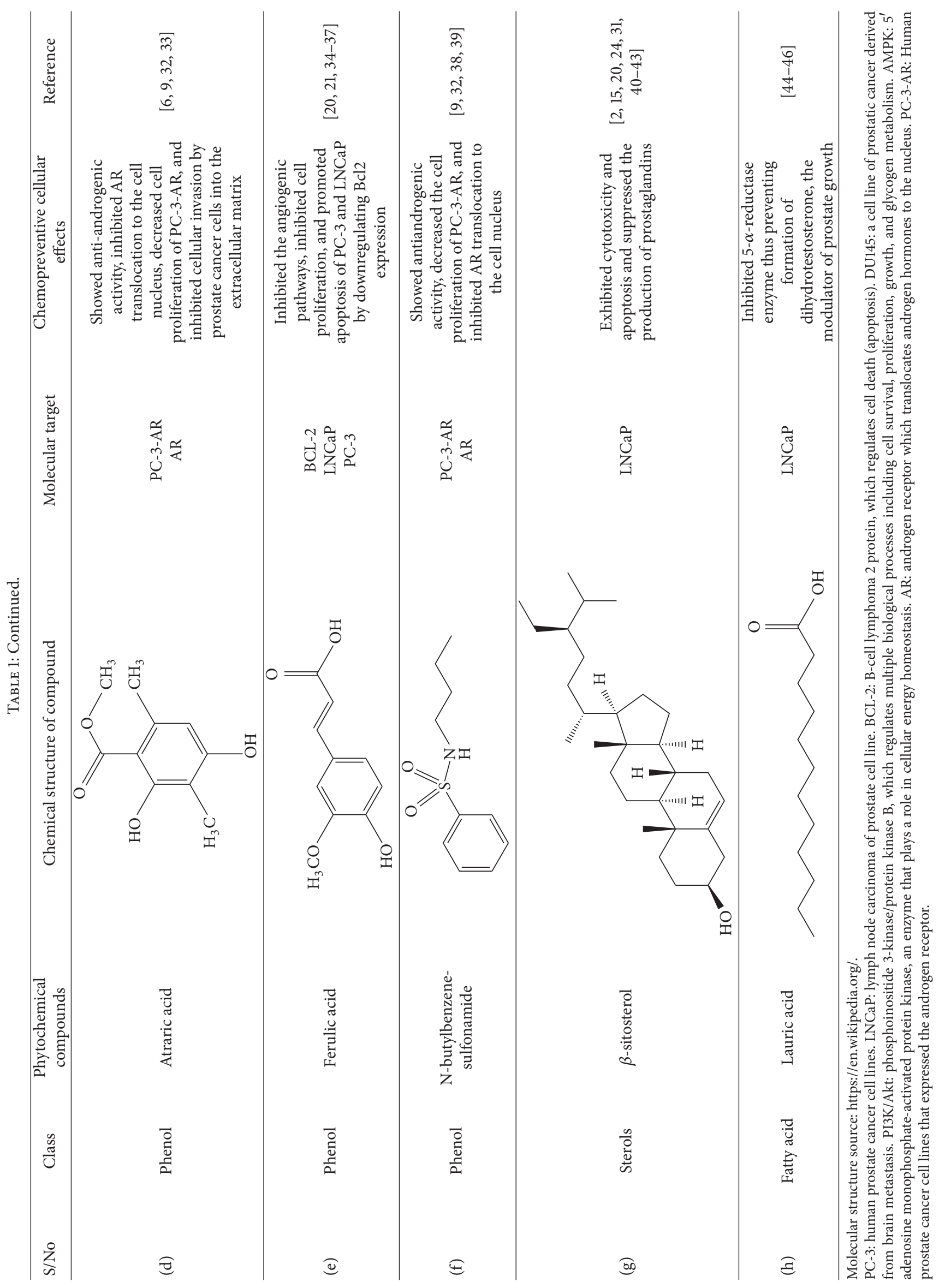


a hormone-refractory and androgen-sensitive cancer [23], and to also inhibit the growth of prostate cancer cells [20]. Therefore, downregulation of BCL- 2 by ursolic acid results in the apoptosis in human prostate cancer cells making the acid a suitable antiprostate cancer agent.

5.2. Oleanolic Acid. Oleanolic acid (Table $1(\mathrm{~b})$ ) is a naturally occurring pentacyclic triterpenoid found in both root and stem bark extracts of $P$. africana [2, 22, 24, 25]. This acid inhibits the survival and proliferation of prostate cancer cells through the induction of apoptosis and interacts with the tumor microenvironment through modulation of multiple signal transduction pathways $[22,26]$. These observations were further confirmed by a study by Li et al. [29] who confirmed that oleanolic acid inhibited the cell viability and proliferation and promoted the cell apoptosis and $G_{0} / G_{1}$ phase cell cycle arrest in prostate cancer PC-3, DU145, and LNCaP cells, in a dose-dependent manner. The same study revealed that oleanolic acid exerted anticancer effects in vitro on PC-3 and DU145 cells by repressing the phosphoinositide 3-kinase (PI3K)/protein kinase B (Akt) pathway [29]. In another study, oleanolic acid exerted antitumor activity by interfering with a metabolic pathway in cancer cells through activation of the enzyme $5^{\prime}$-AMP-activated protein kinase (AMPK) [30]. These studies clearly demonstrated the anticancer properties of oleanolic acid for prostate cancer cells, both in vitro and in vivo, and provided the evidence for its use in further preclinical and clinical studies in prostate cancer patients.

5.3. Atraric Acid (AA). Atraric acid is a naturally occurring phenolic compound and ester (Table 1(d)) found in the bark extract of $P$. africana $[9,32]$. In vitro studies have shown that it has a very strong antiandrogenic activity $[9,32]$, which decreased the cell proliferation of PC-3-AR. However, the growth of PC-3 and non-PCa cells lacking the AR expression was not affected by AA, suggesting an AR-dependent growth inhibitory mechanism imposed by AA [32]. In another study which included a reporter gene assay, $10 \mu \mathrm{M}$ AA repressed the androgen AR-mediated transactivation by about 90\% [32]. AA exhibited a $50 \%$ inhibition level at a concentration of $1 \mu \mathrm{M}$ but failed to repress the AR-mediated transactivation at $0.1 \mu \mathrm{M}$. These findings show that AA represses androgen AR-mediated transactivation at higher concentrations. AA isolated from $P$. africana was found to exhibit similar inhibition of AR function to that of commercially available AA [6] which further signifies the importance of this phytochemical. AA molecules also inhibited AR translocation to the cell nucleus by binding to the receptor which resulted in downregulation of the androgen level [9]. AA also inhibited the cellular invasion of prostate cancer cells into the extracellular matrix, indicating that it may have a protective role against tumor invasion [33]. Furthermore, a study by Hessenkemper et al. [61] strongly showed that AA led to senescenceassociated beta-galactosidase activity, an indication of cellular senescence that resulted into proliferation arrest in PC-3AR. Therefore, the ability of AA to suppress AR and decrease
PC-3 proliferation can be potentially employed in the prostate cancer chemoprevention and chemotherapy.

5.4. Ferulic Acid. Ferulic acid is an abundant phenolic phytochemical (Table 1(e)) found in plant cell wall components of many plants, including $P$. africana $[20,21]$. Studies have shown that ferulic acid isolated from the bark extract of $P$. africana inhibited angiogenic pathways [20,34] and consequently preventing the growth of new blood vessels from preexisting vessels, as well as the growth and spread of prostate cancer [35]. These results were somewhat supported by the data obtained by Mukherji et al. [37], who observed that the inhibition of angiogenic pathways was proven to be an effective strategy for the treatment of several common solid tumors although its definitive role in the management of prostate cancer is yet to be elucidated. In another study conducted by Eroğlu et al. [36], the results revealed that ferulic acid inhibited the cell proliferation and decreased the gene expression of BCL-2 an inhibitor of apoptosis protein 3 (IAP3) in LNCaP cells, resulting in the induction of apoptosis in PC-3 and LNCaP cells. In addition, the authors observed that ferulic acid suppressed the invasion of PC-3 and LNCaP cells [36]. The inhibition of angiogenic pathways and induction of apoptosis by ferulic acid makes it an important therapeutic agent for prostate cancer chemoprevention.

5.5. N-Butylbenzene-Sulfonamide (NBBS). NBBS (Table 1(f)) is one of the compounds naturally found in the bark extract of $P$. africana $[9,32,38]$. It is a sulphur-containing compound that is widely used as a plasticizer in polyacetals and polyamides and it shows high antiandrogenic activity [9]. Although the NBBS phytochemical was found to decrease the cell proliferation of wild-type PC-3-AR cells, the growth of PC-3 and non-PCa cells lacking the AR expression was not affected, suggesting an AR-dependent growth inhibitory mechanism imposed by NBBS [32]. A reporter gene assay that compared AA and NBBS showed that NBBS was less efficacious as an inhibitor of androgen activated ARmediated transactivation, exhibiting $90 \%$ repression only at a higher concentration $(100 \mu \mathrm{M})$ [9]. NBBS also inhibited both endogenous prostate-specific antigen (PSA) expression and growth of human prostate cancer cells [32]. NBBS molecules also inhibited AR translocation to the cell nucleus by binding to it, thereby downregulating the androgen level [9]. Although the limited available literature reports neurotoxicity of NBBS in rabbits [39], experiments with Sprague Dawley male rats showed no observable effects at a dose of $300 \mathrm{mg} / \mathrm{kg} /$ day administered for 27 days [38]. However, deaths of rats were observed at a higher dose of $400 \mathrm{mg} / \mathrm{kg} /$ day after 5 days of dosing [38]. These results were confirmed in a review study by Roell and Baniahmad [32] in which the authors revealed that NBBS only had a slight effect on rats at very high doses and a short duration of treatment and that $P$. africana extracts were well tolerated by humans. Therefore, the effects of NBBS on AR and subsequent decrease in PC-3 proliferation can be explored to maximize its potential for the chemoprevention of prostate cancer. 
5.6. Beta-Sitosterol. Beta-sitosterol is a plant-derived sterol, also known as a phytosterol (Table $1(\mathrm{~g})$ ). The major effects of $P$. africana on prostate cancer have been reported to be due to the presence of this chemical which is present in high concentrations in the plant $[24,40]$. Studies have shown that $\beta$-sitosterol affects the membrane structure and function of tumor as well as the host tissue signal transduction pathways that regulate tumor growth, leading to an apoptotic condition [40]. Furthermore, this phytosterol exhibited anti-inflammatory effects which suppressed the production of prostaglandins thereby preventing the swelling of the prostate [20]. It also inhibited the human prostate tumor cell invasiveness and reduced the release of matrix metalloproteinases [41]. Studies have also shown that $\beta$ sitosterol induced the apoptosis of LNCaP human prostate cancer cells $[42,43]$. These antiprostate cancer activities exhibited by $\beta$-sitosterol can be further developed for the chemoprevention and chemotherapy of prostate cancer.

5.7. Lauric Acid. Lauric acid is a saturated medium-chain fatty acid with a 12-carbon backbone (Table $1(\mathrm{~h})$ ). It is found naturally in various plant and animal fats and oils and is one of the phytochemical components in the stem bark of $P$. africana [20]. It has been found that this acid inhibited the 5 - $\alpha$-reductase enzyme, thus preventing the formation of dihydrotestosterone, the modulator of prostate growth. [20]. Considering that dihydrotestosterone is implicated in the pathogenesis of prostate cancer [45], inhibition of the 5 - $\alpha$-reductase enzyme by lauric acid, resulting in the blockage of testosterone conversion to dihydrotestosterone, plays an integral role in the prevention and treatment of testosterone prostate cancer $[44,45]$. The potential of lauric acid for chemoprevention of prostate cancer has been further supported by a study that showed its ability to inhibit the proliferation of LNCaP cells [46].

\section{Use of $P$. africana in African Traditional Medicine to Treat Prostate Cancer}

Despite the fact that the early detection and commencement of cancer treatment usually increase the chances of survival in developed world, the chances of survival in developing countries are usually much lower since the access to modern cancer diagnostic facilities and effective treatment methods are limited for most people especially for those living in rural areas. In Africa in particular, the herbalists rely on the use of potent herbal medicines to tackle the disease burden. $P$. africana is one of the plants frequently used in many African communities for the treatment of prostate cancer. Thus, according to a study by Ochwang'i et al. [1], the pounded stem bark of $P$. africana is usually mixed with water and drunk as a remedy for Prostate cancer in Kakamega county in Kenya.

\section{Conclusion}

Prostate cancer is still one of the leading causes of death in men worldwide. Therefore, all possible avenues have to be explored in an attempt to tackle the disease. Easily accessible and affordable options, other than the conventional methods of surgery, radiation therapy, cryosurgery, and hormone therapies especially for the poor need to be explored. This review proves that the use of naturally occurring phytochemicals from $P$. africana can be considered for both chemoprevention and chemotherapy of prostate cancer. This plant has a rich history of use in the treatment and management of prostate cancer in ATM. Scientific studies have proven that phytochemicals from $P$. africana have the ability to affect numerous targets associated with the degradation of the prostate cancer cells. Therefore, these pharmacological effects of $P$. africana phytochemicals can be exploited and utilized for the chemoprevention and chemotherapy of prostate cancer. However, more preclinical and clinical studies need to be done to validate these phytochemicals for possible use in the antiprostate cancer drug development. Unfortunately, despite its significant potential for the treatment of prostate cancer and other diseases, improper methods of stem bark harvesting and illegal logging of $P$. africana have made the plant an endangered species. As a result, there is need for advanced $P$. africana propagation techniques to urgently increase its population and distribution range beyond the current level so as to meet the ever increasing demand for this plant and its constituents.

\section{Additional Points}

Limitations. This review has some limitations. First, during our review process we did not include unpublished information and hence our findings could be affected by a publication bias. Second, we might have missed studies or vital information published on sites other than those we focused on. Nevertheless, this review is very significant in that it clearly reveals the potential of $P$. africana for the chemoprevention and chemotherapy of prostate cancer.

\section{Competing Interests}

The authors declare that there is no conflict of interests regarding the publication of this review paper.

\section{Authors' Contributions}

R. Komakech and Y. Kang equally contributed to this manuscript and should be considered co-first authors.

\section{Acknowledgments}

This work was equally supported by grants from Development of Foundational Techniques for the Domestic Production of Authentic Herbal Medicines based on the Establishment of Molecular Authentication System (K17403) \& Establishment of the Evidence for Traditional Korean Medicine Clinical Technology On-Demand (K17121) at Korea Institute of Oriental Medicine (KIOM) through the Ministry of Science, ICT and Future Planning (MSIP), Republic of Korea. 


\section{References}

[1] D. O. Ochwang'i, C. N. Kimwele, J. A. Oduma, P. K. Gathumbi, J. M. Mbaria, and S. G. Kiama, "Medicinal plants used in treatment and management of cancer in Kakamega County, Kenya," Journal of Ethnopharmacology, vol. 151, no. 3, pp. 10401055, 2014.

[2] V. Steenkamp, "Phytomedicines for the prostate," Fitoterapia, vol. 74, no. 6, pp. 545-552, 2003.

[3] N. J. Toyang, H. K. Wabo, E. N. Ateh et al., "In vitro antiprostate cancer and ex vivo antiangiogenic activity of Vernonia guineensis Benth. (Asteraceae) tuber extracts," Journal of Ethnopharmacology, vol. 141, no. 3, pp. 866-871, 2012.

[4] H. Ting, G. Deep, C. Agarwal, and R. Agarwal, "The strategies to control prostate cancer by chemoprevention approaches," Mutation Research, vol. 760, pp. 1-15, 2014.

[5] P. I. Lorenzo and F. Saatcioglu, "Inhibition of apoptosis in prostate cancer cells by androgens is mediated through downregulation of c-Jun N-terminal kinase activation," Neoplasia, vol. 10, no. 5, pp. 418-428, 2008.

[6] S. Schleich, M. Papaioannou, A. Baniahmad, and R. Matusch, "Activity-guided isolation of an antiandrogenic compound of Pygeum africanum," Planta Medica, vol. 72, no. 6, pp. 547-551, 2006.

[7] M.-E. Taplin, G. J. Bubley, T. D. Shuster et al., "Mutation of the androgen-receptor gene in metastatic androgen-independent prostate cancer," New England Journal of Medicine, vol. 332, no. 21, pp. 1393-1398, 1995.

[8] J. Lü, S.-H. Kim, C. Jiang, H. Lee, and J. Guo, "Oriental herbs as a source of novel anti-androgen and prostate cancer chemopreventive agents," Acta Pharmacologica Sinica, vol. 28, no. 9, pp. 1365-1372, 2007.

[9] M. Papaioannou, S. Schleich, D. Roell et al., "NBBS isolated from Pygeum africanum bark exhibits androgen antagonistic activity, inhibits AR nuclear translocation and prostate cancer cell growth," Investigational New Drugs, vol. 28, no. 6, pp. 729$743,2010$.

[10] T. Gilligan and P. W. Kantoff, "Chemotherapy for prostate cancer," Urology, vol. 60, no. 3, pp. 94-100, 2002.

[11] S. Wang, X. Wu, M. Tan et al., "Fighting fire with fire: poisonous Chinese herbal medicine for cancer therapy," Journal of Ethnopharmacology, vol. 140, no. 1, pp. 33-45, 2012.

[12] K. R. Landis-Piwowar and N. R. Iyer, "Cancer chemoprevention: current state of the art," Cancer Growth and Metastasis, vol. 7, pp. 19-25, 2014.

[13] A. Bhanot, R. Sharma, and M. N. Noolvi, "Natural sources as potential anti-cancer agents: a review," International Journal of Phytomedicine, vol. 3, no. 1, pp. 9-26, 2011.

[14] G. M. Cragg, P. G. Grothaus, and D. J. Newman, "Impact of natural products on developing new anti-cancer agents," Chemical Reviews, vol. 109, no. 7, pp. 3012-3043, 2009.

[15] C. A. C. Kadu, A. Parich, S. Schueler et al., "Bioactive constituents in Prunus africana: geographical variation throughout Africa and associations with environmental and genetic parameters," Phytochemistry, vol. 83, pp. 70-78, 2012.

[16] O. M. Grace, H. D. V. Prendergast, A. K. Jäger, and J. Van Staden, "Bark medicines used in traditional healthcare in KwaZuluNatal, South Africa: an inventory," South African Journal of Botany, vol. 69, no. 3, pp. 301-363, 2003.

[17] D. W. Nyamai, W. M. Arika, H. O. Rachuonyo, J. R. Wambani, and M. P. Ngugi, "Herbal management of benign prostatic hyperplasia," Journal of Cancer Science \& Therapy, vol. 8, no. 5, pp. 130-134, 2016.

[18] A. K. Jena, K. Vasisht, N. Sharma, R. Kaur, M. S. Dhingra, and M. Karan, "Amelioration of testosterone induced benign prostatic hyperplasia by Prunus species," Journal of Ethnopharmacology, vol. 190, pp. 33-45, 2016.

[19] L. Jimu, "Threats and conservation strategies for the African Cherry (Prunus africana) in its natural range-a review," Journal of Ecology and Natural Environment, vol. 3, no. 4, pp. 118-130, 2011.

[20] D. W. Nyamai, A. M. Mawia, F. K. Wanbua, A. Njoroge, and F. Matheri, "Phytochemical profile of Prunus africana stem bark from Kenya," Journal of Pharmacognosy and Natural Products, vol. 1, p. 110, 2015.

[21] M. C. Ngule, M. H. Ndiku, and F. Ramesh, "Chemical constituents screening and in vitro antibacterial assessment of Prunus africana bark hydromethanolic extract," Journal of Natural Sciences Research, vol. 4, no. 16, pp. 85-90, 2014.

[22] A. Bishayee, S. Ahmed, N. Brankov, and M. Perloff, "Triterpenoids as potential agents for the chemoprevention and therapy of breast cancer," Frontiers in Bioscience, vol. 16, no. 3, pp. 980-996, 2011.

[23] H. Yang and Q. P. Dou, "Targeting apoptosis pathway with natural terpenoids: implications for treatment of breast and prostate cancer," Current Drug Targets, vol. 11, no. 6, pp. 733$744,2010$.

[24] M. A. Hass, D. M. Nowak, E. Leonova, R. M. Levin, and P. A. Longhurst, "Identification of components of Prunus africana extract that inhibit lipid peroxidation," Phytomedicine, vol. 6, no. 5, pp. 379-388, 1999.

[25] C. Fourneau, R. Hocquemiller, and A. Cavé, “Triterpenes from Prunus africana bark," Phytochemistry, vol. 42, no. 5, pp. 13871389, 1996.

[26] S. H. Safe, P. L. Prather, L. K. Brents, G. Chadalapaka, and I. Jutooru, "Unifying mechanisms of action of the anticancer activities of triterpenoids and synthetic analogs," Anti-Cancer Agents in Medicinal Chemistry, vol. 12, no. 10, pp. 1211-1220, 2012.

[27] P. E. Czabotar, G. Lessene, A. Strasser, and J. M. Adams, "Control of apoptosis by the BCL-2 protein family: implications for physiology and therapy," Nature Reviews Molecular Cell Biology, vol. 15, no. 1, pp. 49-63, 2014.

[28] V. R. Yadav, S. Prasad, B. Sung, R. Kannappan, and B. B. Aggarwal, "Targeting inflammatory pathways by triterpenoids for prevention and treatment of cancer," Toxins, vol. 2, no. 10, pp. 2428-2466, 2010.

[29] X. Li, Y. Song, P. Zhang et al., "Oleanolic acid inhibits cell survival and proliferation of prostate cancer cells in vitro and in vivo through the PI3K/Akt pathway," Tumor Biology, vol. 37, no. 6, pp. 7599-7613, 2016.

[30] J. Liu, L. Zheng, N. Wu et al., "Oleanolic acid induces metabolic adaptation in cancer cells by activating the amp-activated protein kinase pathway," Journal of Agricultural and Food Chemistry, vol. 62, no. 24, pp. 5528-5537, 2014.

[31] F. Maiyo, R. Moodley, and M. Singh, "Phytochemistry, cytotoxicity and apoptosis studies of $\beta$-sitosterol-3-O-Glucoside and $\beta$-amyrin from Prunus africana," The African Journal of Traditional, Complementary and Alternative Medicines, vol. 13, no. 4,2016

[32] D. Roell and A. Baniahmad, "The natural compounds atraric acid and N-butylbenzene-sulfonamide as antagonists of the 
human androgen receptor and inhibitors of prostate cancer cell growth," Molecular and Cellular Endocrinology, vol. 332, no. 1-2, pp. 1-8, 2011.

[33] M. Papaioannoua, A. Söderholma, W. Honge et al., "Computational and functional analysis of the androgen receptor antagonist atraric acid and its derivatives," Anti-Cancer Agents in Medicinal Chemistry, vol. 13, no. 5, pp. 801-810, 2013.

[34] G.-W. Yang, J.-S. Jiang, and W.-Q. Lu, "Ferulic acid exerts anti-angiogenic and anti-tumor activity by targeting fibroblast growth factor receptor 1-mediated angiogenesis," International Journal of Molecular Sciences, vol. 16, no. 10, pp. 24011-24031, 2015.

[35] B. Nicholson and D. Theodorescu, "Angiogenesis and prostate cancer tumor growth," Journal of Cellular Biochemistry, vol. 91, no. 1, pp. 125-150, 2004.

[36] C. Eroğlu, M. Seçme, G. Bağc1, and Y. Dodurga, “Assessment of the anticancer mechanism of ferulic acid via cell cycle and apoptotic pathways in human prostate cancer cell lines," Tumor Biology, vol. 36, no. 12, pp. 9437-9446, 2015.

[37] D. Mukherji, S. Temraz, D. Wehbe, and A. Shamseddine, "Angiogenesis and anti-angiogenic therapy in prostate cancer," Critical Reviews in Oncology/Hematology, vol. 87, no. 2, pp. 122131, 2013.

[38] C. V. Rider, K. S. Janardhan, D. Rao, J. P. Morrison, C. A. McPherson, and G. J. Harry, "Evaluation of N-butylbenzenesulfonamide (NBBS) neurotoxicity in Sprague-Dawley male rats following 27-day oral exposure," NeuroToxicology, vol. 33, no. 6, pp. 1528-1535, 2012.

[39] M. J. Strong, R. M. Garruto, A. V. Wolff, S. M. Chou, S. D. Fox, and R. Yanagihara, "N-Butyl benzenesulfonamide: a neurotoxic plasticizer inducing a spastic myelopathy in rabbits," Acta Neuropathologica, vol. 81, no. 3, pp. 235-241, 1991.

[40] N. Shenouda, M. Sakla, L. Newton et al., "Phytosterol Pygeum africanum regulates prostate cancer in vitro and in vivo," Endocrine, vol. 31, no. 1, pp. 72-81, 2007.

[41] F. A. Attiga, P. M. Fernandez, A. T. Weeraratna, M. J. Manyak, and S. R. Patierno, "Inhibitors of prostaglandin synthesis inhibit human prostate tumor cell invasiveness and reduce the release of matrix metalloproteinases," Cancer Research, vol. 60, no. 16, pp. 4629-4637, 2000.

[42] R. L. Von Holtz, C. S. Fink, and A. B. Awad, “ $\beta$-Sitosterol activates the sphingomyelin cycle and induces apoptosis in LNCaP human prostate cancer cells," Nutrition and Cancer, vol. 32, no. 1, pp. 8-12, 1998.

[43] A. B. Awad, Y. Gan, and C. S. Fink, "Effect of $\beta$-sitosterol, a plant sterol, on growth, protein phosphatase $2 \mathrm{~A}$, and phospholipase $\mathrm{D}$ in LNCaP cells," Nutrition and Cancer, vol. 36, no. 1, pp. 7478, 2000.

[44] L. Goldenberg, A. So, N. Fleshner, R. Rendon, D. Drachenberg, and M. Elhilali, "The role of 5-alpha reductase inhibitors in prostate pathophysiology: is there an additional advantage to inhibition of type 1 isoenzyme?" Journal of the Canadian Urological Association, vol. 3, no. 3, pp. S109-S114, 2009.

[45] H. J. Niederprüm, H. U. Schweikert, J. W. Thüroff, and K. S. Zänker, "Inhibition of steroid $5 \alpha$-reductase activity by aliphatic fatty acids: candidates for chemoprevention of prostate cancer," Annals of the New York Academy of Sciences, vol. 768, no. 1, pp. 227-230, 1995.

[46] J. Liu, K. Shimizu, and R. Kondo, "Anti-androgenic activity of fatty acids," Chemistry \& Biodiversity, vol. 6, no. 4, pp. 503-512, 2009.
[47] S. Y. Kim, J. L. England, J. A. Sharma, and T. Njoroge, "Gestational diabetes mellitus and risk of childhood overweight and obesity in offspring: a systematic review," Experimental Diabetes Research, vol. 2011, Article ID 541308, 9 pages, 2011.

[48] J. Lin, S. Chen, S. Li, M. Lu, Y. Li, and Y. Su, "Efficacy and safety of chinese medicinal herbs for the treatment of hyperuricemia: a systematic review and meta-analysis," Evidence-Based Complementary and Alternative Medicine, vol. 2016, Article ID 2146204, 12 pages, 2016.

[49] J. B. Hall, E. M. O’Brian, and F. L. Sinclair, Prunus africanaA Monograph, School of Agriculture and Forest Sciences, University of Wales, ICRAF, Bangor, UK, 2000.

[50] D. Biswajit, N. Ahmed, and S. Pushkar, "Prunus diversity-early and present development: a review," International Journal of Biodiversity and Conservation, vol. 3, no. 14, pp. 721-734, 2011.

[51] K. Stewart, Effects of Bark Harvest and Other Human Activity on Populations of the African Cherry (Prunus africana) on Mount Oku, Cameroon, Elsevier, 2009.

[52] A. B. Cunningham, E. Ayuk, S. Franzel, B. Duguma, and C. Asanga, "An economic evaluation of Medical tree cultivation; Prunus africana in Cameroon," in People and Working Paper 10., UNESCO, 2002.

[53] C. Orwa, A. Mutua, R. Kindt, R. Jamnadass, and A. Simons, Agroforestree Database: A Tree Reference and Selection Guide Version 4.0., World Agroforestry Centre, Nairobi, Kenya, 2009.

[54] G. Bodeker, C. Van'T Klooster, and E. Weisbord, "Prunus africana (Hook.f.) Kalkman: the overexploitation of a medicinal plant species and its legal context," Journal of Alternative and Complementary Medicine, vol. 20, no. 11, pp. 810-822, 2014.

[55] K. M. Stewart, "The African cherry (Prunus africana): can lessons be learned from an over-exploited medicinal tree?" Journal of Ethnopharmacology, vol. 89, no. 1, pp. 3-13, 2003.

[56] I. Dawson, J. Were, and A. Lengkeek, "Conservation of Prunus africana, an over-exploited African medicinal tree," Forest Genetic Resources 28, FAO, Rome, Italy, 2000.

[57] A. Sofowora, E. Ogunbodede, and A. Onayade, "The role and place of medicinal plants in the strategies for disease prevention," The African Journal of Traditional, Complementary, and Alternative Medicines, vol. 10, no. 5, pp. 210-229, 2013.

[58] S.-J. Jeong, W. Koh, B. Kim, and S.-H. Kim, "Are there new therapeutic options for treating lung cancer based on herbal medicines and their metabolites?" Journal of Ethnopharmacology, vol. 138, no. 3, pp. 652-661, 2011.

[59] S. M. A. Margalef, P. R. Barzanti, R. J. Puigjaner, R. J. Morote, and T. T. M. Okatsu, "Antimitogenic effect of Pygeum africanum extracts on human prostatic cancer cell lines and explants from benign prostatic hyperplasia," Archivos Españoles de Urología, vol. 56, no. 4, pp. 369-378, 2003.

[60] W. L. W. Hsiao and L. Liu, "The role of traditional Chinese herbal medicines in cancer therapy from TCM theory to mechanistic insights," Planta Medica, vol. 76, no. 11, pp. 11181131, 2010.

[61] W. Hessenkemper, J. Roediger, S. Bartsch et al., "A natural androgen receptor antagonist induces cellular senescence in prostate cancer cells," Molecular Endocrinology, vol. 28, no. 11, pp. 1831-1840, 2014. 


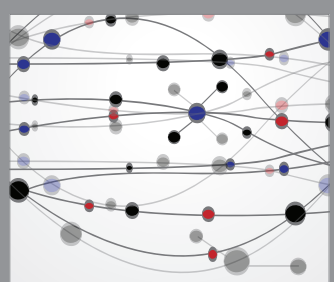

The Scientific World Journal
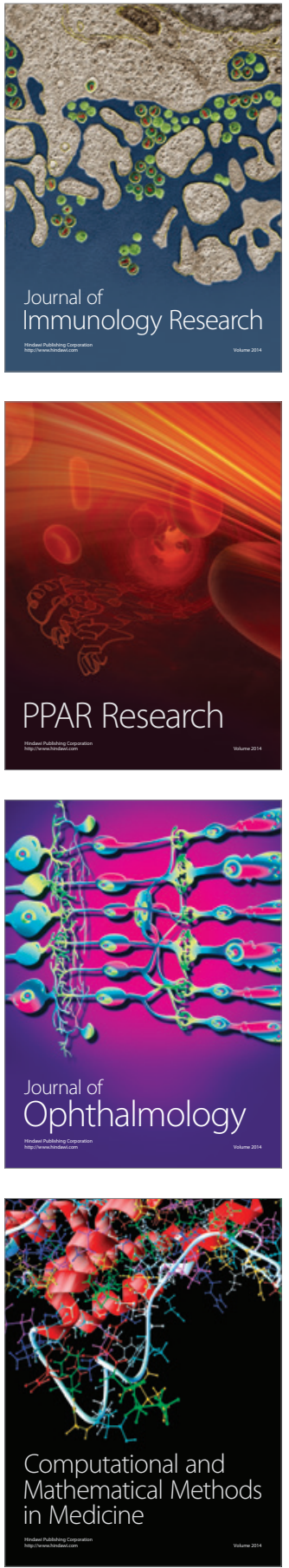

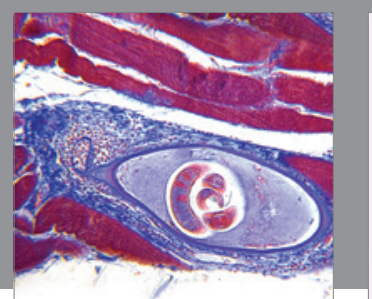

Gastroenterology Research and Practice
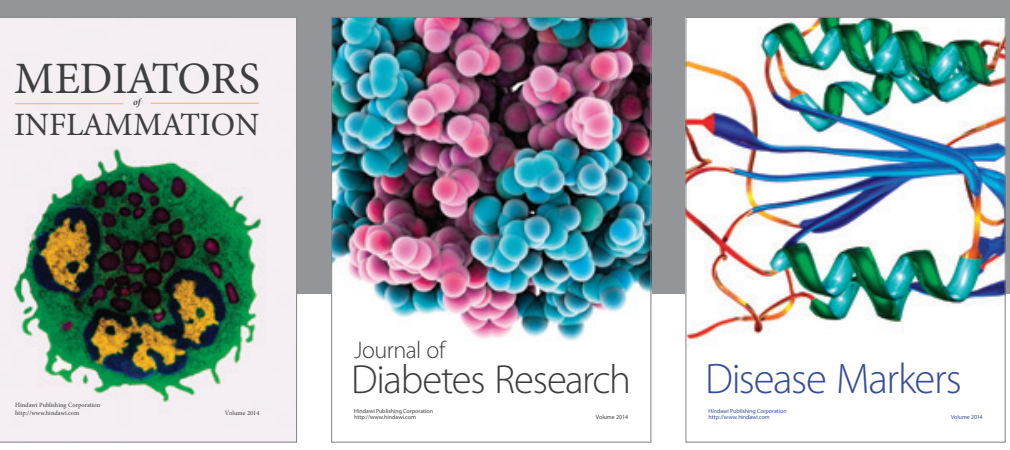

Disease Markers

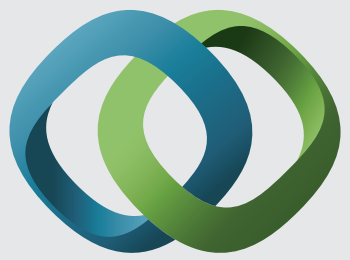

\section{Hindawi}

Submit your manuscripts at

https://www.hindawi.com
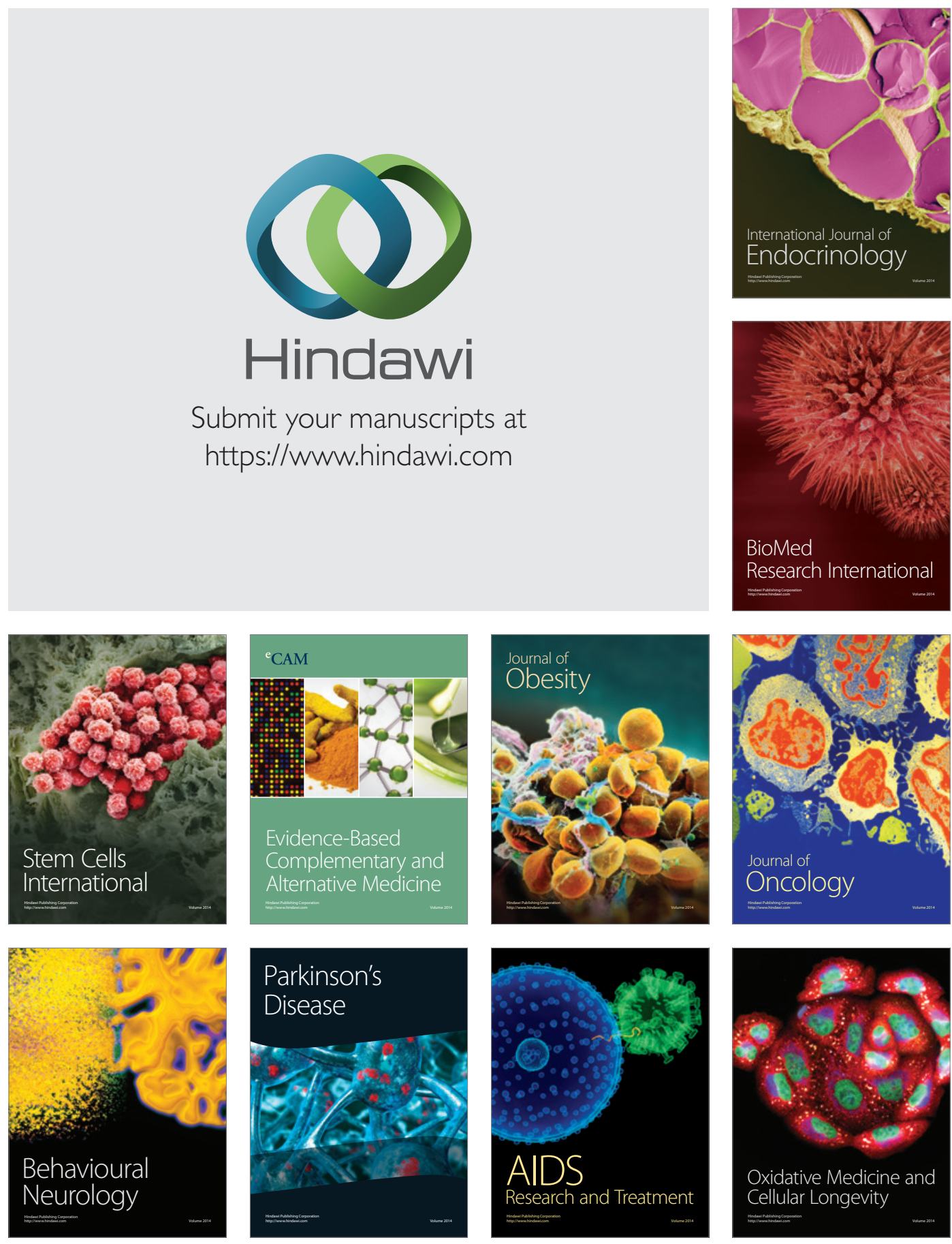